\title{
Investigating the Local Stress of Car Deck Ro-Ro 5000 GT
}

\author{
Alamsyah $^{\mathrm{a}, *}$, Ahmed Reza Falevi ${ }^{\mathrm{b}}$, Amalia Ika Wulandari ${ }^{\mathrm{c}}$, Muhammad Uswah Pawara ${ }^{\mathrm{d}}$, Wira Setiawan ${ }^{\mathrm{e}}$, Andi \\ Mursyid Nugraha Arifuddin ${ }^{\mathrm{f}}$ \\ ${ }^{a}$ Naval Architecture Program, Kalimantan Institut of Technology. Email: alamsyah@lecturer.itk.ac.id \\ bNaval Architecture Program, Kalimantan Institut of Technology. Email: Ahmedrezafalevi@yahoo.co.id \\ ${ }^{\mathrm{c} N a v a l}$ Architecture Program, Kalimantan Institut of Technology. Email: amaliaikaw@lecturer.itk.ac.id \\ ${ }^{\mathrm{d} N a v a l}$ Architecture Program, Kalimantan Institut of Technology. Email: uswah.pawara@lecturer.itk.ac.id \\ eNaval Architecture Program, Kalimantan Institut of Technology. Email: wira@lecturer.itk.ac.id

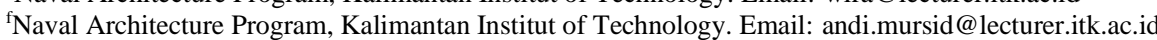

\begin{abstract}
A deck construction must be strong enough that it will not suffer structural damage if it works under a given load. In this case, the strain stress becomes very important from the strength of the deck, as the one that affects the strength of the deck construction, one of which is the stiffener distance. This study aims to analyze the maximum strain stress on the deck of the Ro-Ro Ferry. The method used is Finite Element Method (FEM) by varying the stiffener distance in the deck construction. The research results obtained, namely the variation of the stiffener distance of $600 \mathrm{~mm} .285 .5 \mathrm{~N} / \mathrm{mm}^{2}$ and the maximum strain is $1.76 \times 10^{-3} \mathrm{~mm}$, at a variation of $700 \mathrm{~mm}$ stiffener distance the maximum stress is $378,075 \mathrm{~N} / \mathrm{mm}^{2}$ and the maximum strain is $1.77 \times 10^{-3} \mathrm{~mm}$, at a stiffener distance variation $800 \mathrm{~mm}$ the maximum stress released is $383,737 \mathrm{~N} / \mathrm{mm}^{2}$ and the maximum strain released is $1.78 \mathrm{x}^{-3} \mathrm{~mm}$, at $900 \mathrm{~mm}$ stiffener distance variations the maximum stress is $389,188 \mathrm{~N} / \mathrm{mm}^{2}$ and the maximum strain released is $1.79 \times 10^{-3} \mathrm{~mm}$, at variations in distance stiffener $1000 \mathrm{~mm}$ the maximum stress released is $425,388 \mathrm{~N} / \mathrm{mm}^{2}$ and the maximum strain released is $1.8 \times 10^{-3} \mathrm{~mm}$, The value of strain increasingly increases followed by the farther distance of the stiffener equal $0.6 \%$, and the stress value is at a variation increasingly increases followed by the farther distance of the stiffener equal $12.24 \%$.
\end{abstract}

Keywords: Car deck; stiffener; stress; strain

\section{Introduction}

Ro-Ro ferry is one of the means of transportation used for crossings in archipelagic countries such as Indonesia. This ship is used to transport people and their vehicles. On the deck, the ship receives a fairly large load. This requires that the ship is always in a safe condition, especially in terms of its strength of construction. The transverse strength of a ship is the ability of the transverse structure of the ship to maintain the cross-sectional shape of the ship against disturbances of loads acting on the ship such as deck loads, side loads, and bottom loads. So it is clear that the main components of the ship structure are the lower structure, side structures, and deck structures [1].

Factors that affect the strength of the construction include the distance between the tusks, the distance between the stiffeners, the unfolded length, the plate thickness, etc. The normal strength of a ship's steel structure has a minimum melting point of REH 235 $\mathrm{N} / \mathrm{mm}^{2}$ and a tensile strength of Rm $400-520 \mathrm{~N} / \mathrm{mm}^{2}$ (BKI, 2021). To meet the allowable stress (yield strength) in construction, it is customary to increase the

*Corresponding author. Tel.: +6285-242-800-578

Jl. Soekarno-Hatta KM. 15 Kampus ITK Karang Joang

Balikpapan, Indonesia, 76127 construction modulus value by adding a thick insert plate or longitudinal carling [2].

Types of structural problems include stress analysis, frame analysis, buckling, and vibration analysis [3]. Loads that can affect the local structure and must be considered in the design of the transverse construction of the ship consists of two parts, namely: buoyancy and gravity. The upward pressure results from the distribution of hydrostatic pressure in the outer plane of the immersed hull. Gravity is the largest downward force on ships and their contents [4]. As a result of these loads, all parts of the ship's construction experience some type of stress. There are several factors that cause the actual stress distribution to be different from the ideal stress distribution. Due to the transverse shear stress, distortion occurs based on the length of the hull girder cross-section [5].

In problems involving complex geometries, such as problems applying to complex structures, it is generally difficult to solve them through mathematical analysis. This is because mathematical analysis requires a quantity or value that must be known at each point in the structure under study. Solving the analysis of complex geometrical differential equations, complex loading, is not easy to obtain. Nevertheless, the formulation of the finite element method can be used to solve these problems [3]. 
The new method based on virtual displacement is the world's last solution. Applied mathematics problems and solutions are still being developed along with the development of computer science [6]. Finite element analysis is a numerical technique. In this method, By using this package, one can analyze several complex structures [7]. As a numerical method, it is used to solve technical and mathematical problems of a physical phenomenon. The types of physical and mathematical problems that can be solved by the method are structural and non-structural analysis. By using the method, all the complexity of the problem, such as various shapes, boundary conditions, and loads can be maintained but the solutions obtained are only approximate. This is due to its diversity and flexibility as an analytical tool. Rapid improvements in computer hardware technology and reduction in computer costs have driven this method because computers are a basic requirement for the application of this method. A number of popular brand element analysis packages are now commercially available to simplify complex structural analysis [8].

In this study, the strength of the deck construction of ro-ro ferry will be examined by modeling it in the FEM application. Modeling is done to determine the amount of stress and strain in construction. Stress is a static amount; it is a measure of the stress of structural materials. On the other hand, strain is total kinematic; it measures structural deformation. However, deformation depends on the loads acting on the structure. Therefore, stress and strain are not independent. The physical relationships that connect these numbers are called constitutive laws. It describes the structural behavior of the material under load. It depends on the material and can only be obtained with the help of experiments [9].

One of the assessments carried out to determine the strength of the construction is to estimate the stress ratio obtained by comparing the stress that occurs in the construction due to external loads working on the ship [10]. According to BKI 2021, a good stress ratio for working on ship construction is still smaller than $1(<1)$ [11].

\section{Methods}

This research is a quantitative research that takes the sample ro-ro ferry. The object of research was the stiffener of the vehicle 01 deck on the Ro-Ro Ferry, namely KMP Legundi 5000GT as shown in Fig. 1.
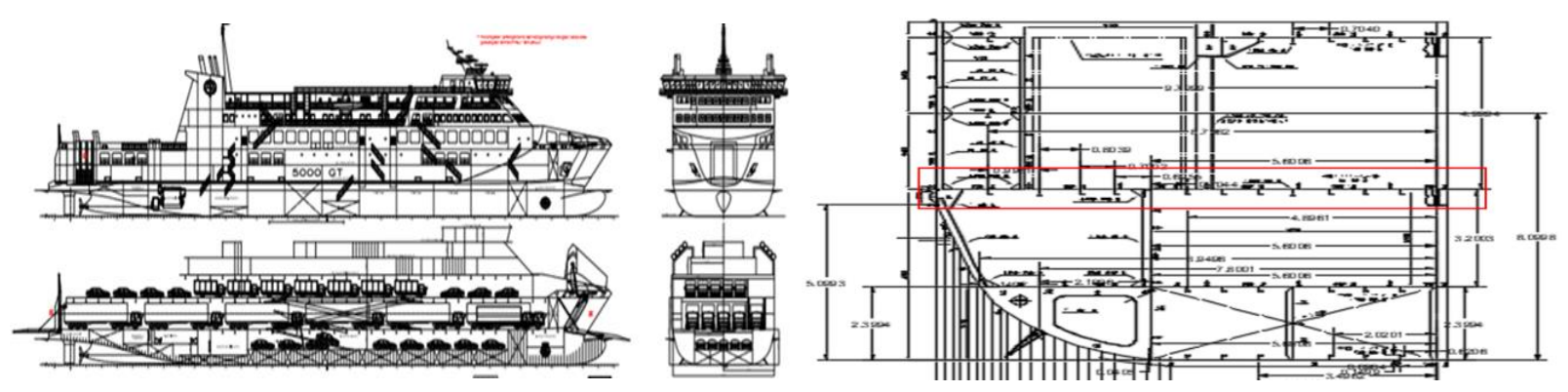

Figure 1. GA and midship construction of ferry ro-ro

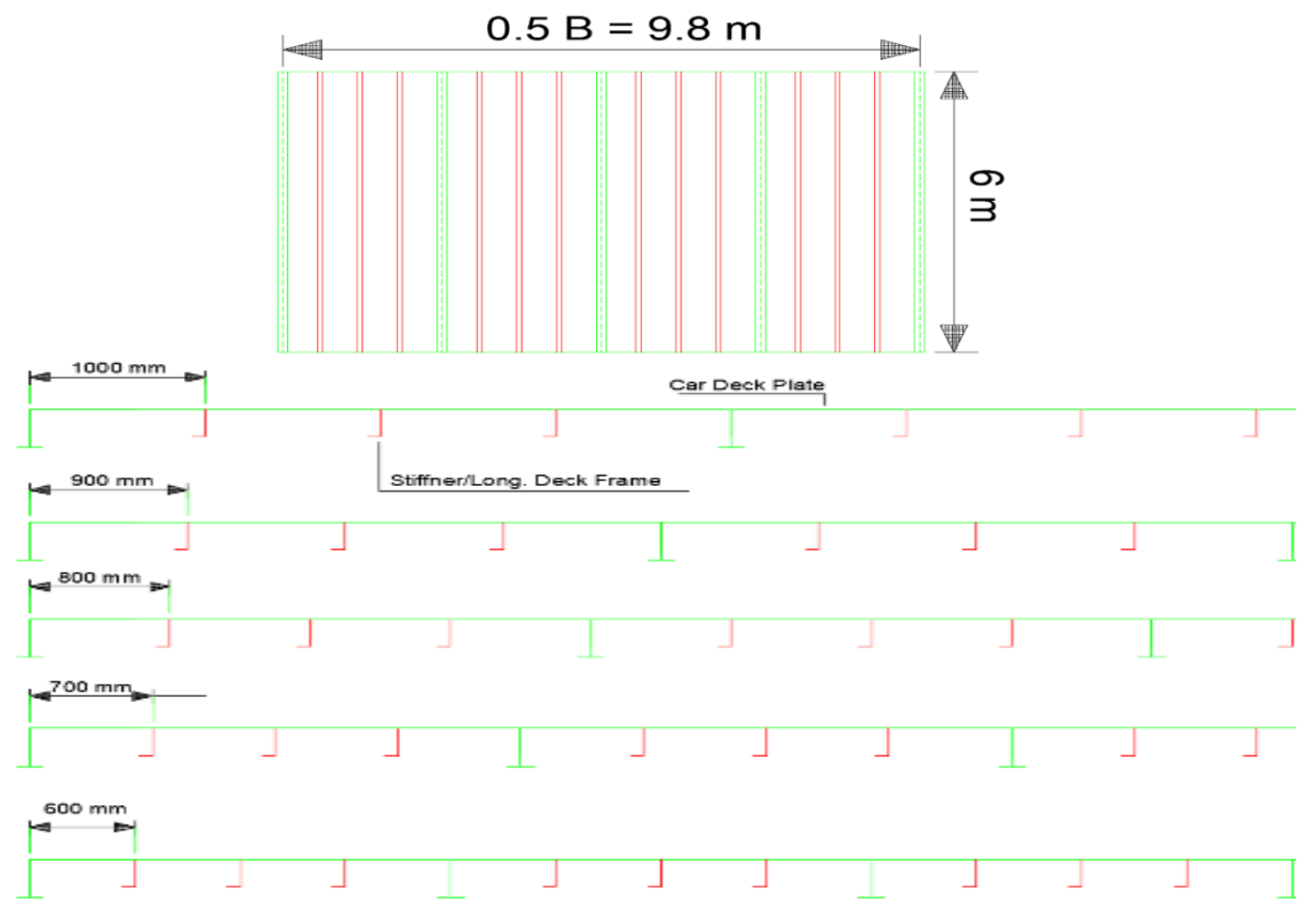

Figure 2. Plan view and transfer view of car deck 
Figure 1 shows the red line marking on the vehicle deck which is the object of the study. The detailed illustration of the vehicle deck construction and the stiffener variation plan is shown in Fig. 2. Figure 2 is then converted to a 3D model using an FE-based application by taking the width of the ship on the ro-ro ferry car deck and the length of the deck model of $6 \mathrm{~m}$ then varying the stiffener distance shown in Fig. 3.

Furthermore, the meshing process is carried out on the 3D car deck model as one of the steps that are passed when using the FE analysis shown in Fig. 4. The mesh size used is $300 \mathrm{~mm}$ with the mesh type is hexahedron. As shown in Fig. 4. The next stage is to provide the boundary conditions on the $3 \mathrm{D}$ car deck model in the form of vehicle support and load shown in Fig. 5.

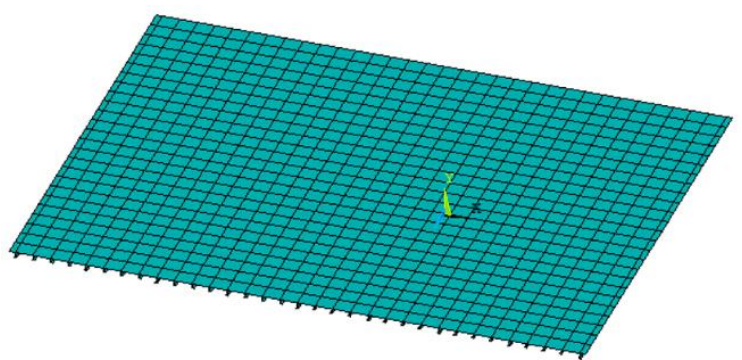

Figure 3. 3D modeling of car deck

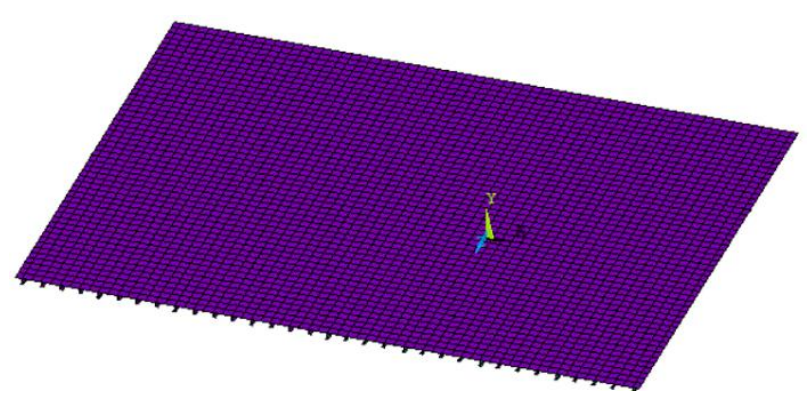

Figure 4. Meshing of 3D modeling car deck

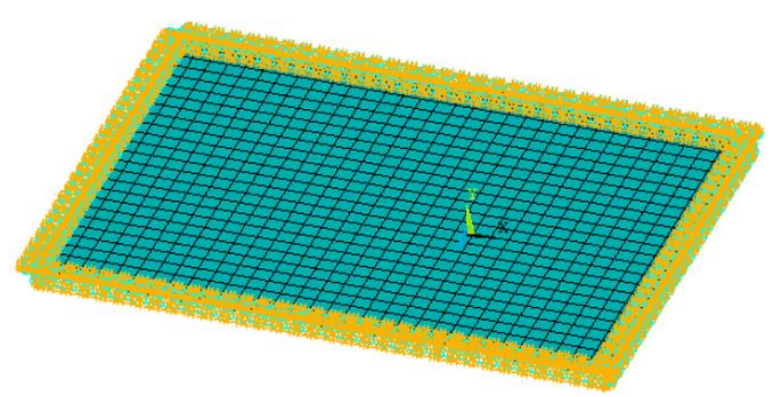

(a)

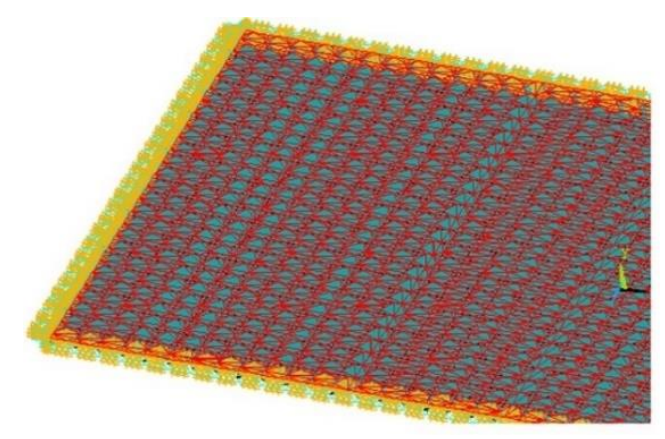

(b)

Figure 5. (a) input fixed support; (b) input pressure load
Figure 5a shows the pedestal input in the form of fixed support given around the 3D car deck model. Whereas Figure $5 b$ shows the load input given in the form of the total load of the trailer truck according to the load case during operation [12] which is on the car deck of $1.18 \times 10^{-2} \mathrm{~N} / \mathrm{mm}^{2}$ which form of load pressure. The results of the running of the FEM application are NLFEA in the form of maximum stress values The output parameters used for each variation stiffener distance are the value of the maximum stress and strain against the maximum load acting on the car deck structure.

Stress is defined as the amount of force acting per unit area. There are two types of stress: normal stress and shear stress. Normal stress $(\sigma)$ is a measure of the normal force or axial force per unit area [13]. Stress is the force of broad unity. When an object is subjected to a force, the stress is the ratio between the size of the force to the area to which the force is applied. If the force applied is perpendicular to the surface of the object (the area to be calculated), then the stress is normal stress. If the force applied to the object is tangential to the surface of the object, the stress is the shear stress [13].

$$
\sigma=\frac{F}{A}
$$

where $\sigma=$ stress $(\mathrm{Pa}) ; F=$ force $(\mathrm{N}) ; A=$ cross-sectional area $\left(\mathrm{mm}^{2}\right)$. The strain (strain) is defined as the ratio between the increase in length or shortness of the stem and the size initially stated:

$$
\varepsilon=\frac{\Delta L}{L}
$$

where $\varepsilon=\operatorname{strain}(\mathrm{mm}) ; \Delta L=$ increase in length $(\mathrm{mm}) ; L=$ initial length $(\mathrm{mm})$.

\section{Results and Discussion}

This research shows that the calculation of strength is obtained using an application based on the Finite Element Method (FEM) on the car deck of a ro-ro ferry. The simulation results at each variation of the stiffener distance can be seen in Fig. 6 .

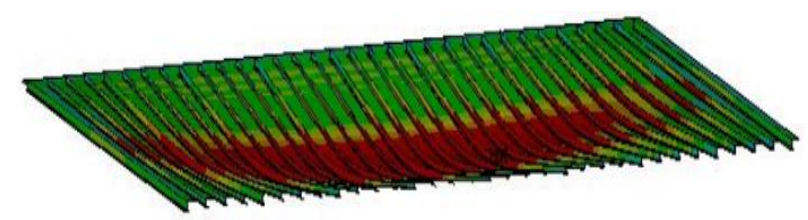

(a)

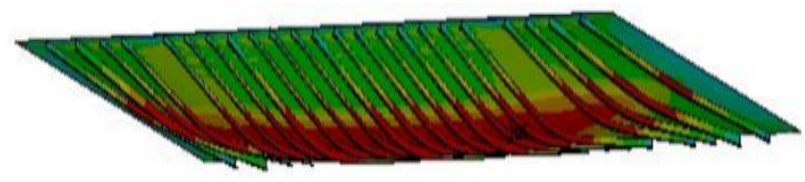

(b)

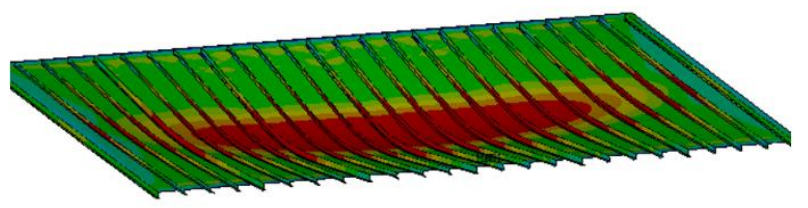

(c) 


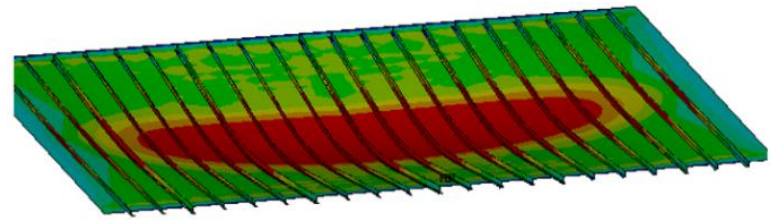

(d)

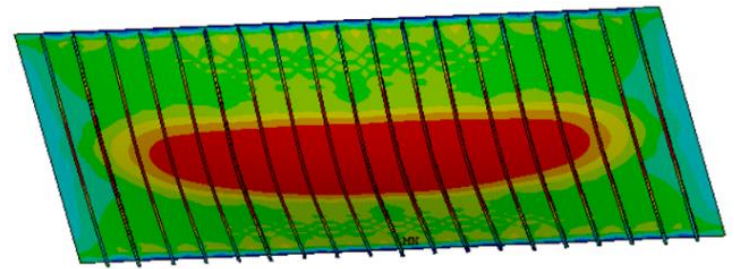

(e)

Figure 6. (a) $600 \mathrm{~mm}$ spacing; (b) $700 \mathrm{~mm}$ spacing; (c) $800 \mathrm{~mm}$ spacing; (d) $900 \mathrm{~mm}$ spacing; (e) $1000 \mathrm{~mm}$ spacing

Table 1 shows the value of von misses stress that occurs in the car deck model with variations in the stiffener distance starting from $600 \sim 1000 \mathrm{~mm}$. Von misses stress and deformation values for each stiffener distance are summarized in Table 1.

Table 1 shows that the simulation results of the car deck stiffener distance variation of $600 \mathrm{~mm}$, the maximum stress is $285.5 \mathrm{~N} / \mathrm{mm}^{2}$, and the maximum strain is $1.76 \times 10^{-3} \mathrm{~mm}$. For a stiffener distance of 700 $\mathrm{mm}$, the maximum stress released is $378,075 \mathrm{~N} / \mathrm{mm}^{2}$, and the maximum strain released is $1.77 \times 10^{-3} \mathrm{~mm}$. For stiffener distance of $800 \mathrm{~mm}$, the maximum stress released is $383,737 \mathrm{~N} / \mathrm{mm}^{2}$ and the maximum strain released is $1.78 \times 10^{-3} \mathrm{~mm}$. While the stiffener distance is $900 \mathrm{~mm}$. The maximum stress released is 389,188 $\mathrm{N} / \mathrm{mm}^{2}$ and the maximum strain released is $1.79 \times 10^{-3}$ $\mathrm{mm}$ and the maximum stress emitted is $425,388 \mathrm{~N} / \mathrm{mm}^{2}$ and the maximum strain released is $1.8 \times 10^{-3} \mathrm{~mm}$.

Based on the analysis, the results of the stress-strain acting on the car deck structure are obtained, by considering the boundary conditions, the stress-strain relationship curve for each stiffener distance variation is shown in Fig. 7.

Figure 7 shows the car deck with a stiffener distance variation of $600 \mathrm{~mm}$ with a stress value of $0 \mathrm{~N} / \mathrm{mm}^{2}$ to $221,798 \mathrm{~N} / \mathrm{mm}^{2}$, the car deck is still linear or within the proportionality limit and then when the car deck with a value of $223,095 \mathrm{~N} / \mathrm{mm}^{2}$ is already at the elasticity limit or the addition of the stress-strain value on the graph has reached non-linear and is in a plastic condition that will reach the ultimate stress.

Table 1. Von misses stress and deformation of car deck

\begin{tabular}{ccc}
\hline $\begin{array}{c}\text { Space of Stiffener } \\
(\mathrm{mm})\end{array}$ & $\begin{array}{c}\text { Von misses stress } \\
\left(\mathrm{N} / \mathrm{mm}^{2}\right)\end{array}$ & $\begin{array}{c}\text { Deformation } \\
(\mathrm{mm})\end{array}$ \\
\hline 600 & 285.5 & $1.76 \times 10^{-3}$ \\
700 & 378.075 & $1.77 \times 10^{-3}$ \\
800 & 383.737 & $1.78 \times 10^{-3}$ \\
900 & 389.188 & $1.79 \times 10^{-3}$ \\
1000 & 425.388 & $1.8 \times 10^{-3}$ \\
\hline
\end{tabular}

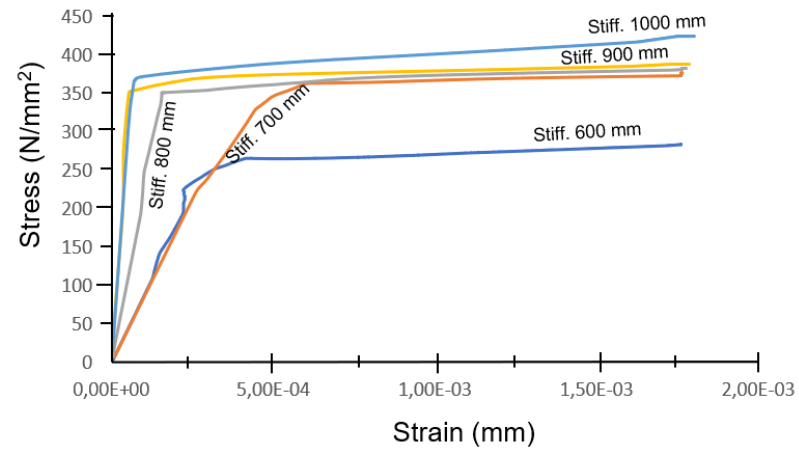

Figure 7. Stress-strain curve of car deck

The car deck with a stiffener distance variation of 700 $\mathrm{mm}$ with a stress value of $0 \mathrm{~N} / \mathrm{mm}^{2}$ to $313,414 \mathrm{~N} / \mathrm{mm}^{2}$ the car deck is still linear or still within the proportionality limit and then when the car deck ship with a stress value of $322,188 \mathrm{~N} / \mathrm{mm}^{2}$ is already at the elasticity limit or the addition of the stress-strain value on the graph has reached non-linear and is in a plastic condition that will reach the ultimate stress.

Car decks with stiffener distance variations of 800 $\mathrm{mm}$ with a stress value of $0 \mathrm{~N} / \mathrm{mm}^{2}$ to $340,605 \mathrm{~N} / \mathrm{mm}^{2}$ the car deck is still linear or within the proportionality limit and then when the ship car deck with a stress value of $345,746 \mathrm{~N} / \mathrm{mm}^{2}$ is already at the elasticity limit or the addition of the stress-strain value on the graph has reached non-linear and is in a plastic condition that will reach the ultimate stress.

Car decks with stiffener distance variations of 900 $\mathrm{mm}$ with a voltage value of $0 \mathrm{~N} / \mathrm{mm}^{2}$ to $345,832 \mathrm{~N} / \mathrm{mm}^{2}$ the car deck is still linear or still within the proportionality limit and then when the ship car deck with a stress value of $351,203 \mathrm{~N} / \mathrm{mm}^{2}$ is already at the elasticity limit or The added value of stress and strain on the graph has reached non-linear and is in a plastic condition that will reach the ultimate stress.

Car deck with stiffener distance variation of $1000 \mathrm{~mm}$ with a voltage value of $0 \mathrm{~N} / \mathrm{mm}^{2}$ to $362,864 \mathrm{~N} / \mathrm{mm}^{2}$ the car deck is still linear or still within the proportionality limit and then when the car deck ship with a stress value of $366,445 \mathrm{~N} / \mathrm{mm}^{2}$ is already at the elasticity limit or the addition of the stress-strain value on the graph has reached non-linear and is in a plastic condition that will reach the ultimate stress.

Based on the analysis, it is detected that the results of stress and strain acting on each of the elements in the car deck structure, by considering the variations in the stiffener distance that occur in each case, then a comparison of the stress values is obtained in Fig. 8.

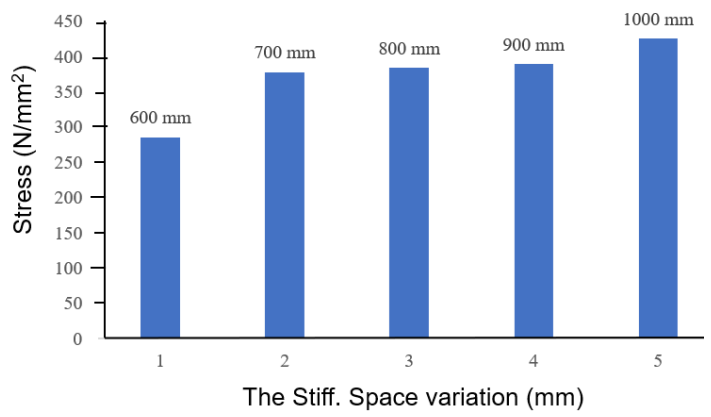

Figure 8. Stress influence of stiffener space 
Figure 8 shows the stress value at the variation of the distance between $600 \mathrm{~mm}$ stiffener is $285.5 \mathrm{~N} / \mathrm{mm}^{2}$, the variation of the distance between $700 \mathrm{~mm}$ stiffener is $378,075 \mathrm{~N} / \mathrm{mm}^{2}$, the variation of the distance between $800 \mathrm{~mm}$ stiffener is $383,737 \mathrm{~N} / \mathrm{mm}^{2}$, at variations in the distance $900 \mathrm{~mm}$ stiffener is $389,188 \mathrm{~N} / \mathrm{mm}^{2}$ and the variation of the distance between $1000 \mathrm{~mm}$ stiffener is $425,388 \mathrm{~N} / \mathrm{mm}^{2}$. The highest stress value is in the variation of the distance between $1000 \mathrm{~mm}$ stiffener. There is an increase in the value of the stress as the distance between the stiffeners increases with an average percentage increase of $12.24 \%$. This is in line with Amalia's 2019 research that the decrease in load is inversely proportional to the increase in frame distance, the farther the frame distance, the smaller the load required for the plate to buckle [14].

Based on the analysis, the results of the stress-strain acting on each of the elements in the car deck structure are obtained, by considering the variation in stiffener distance that occurs in each case, the comparison of the strain values is shown in Fig. 9.

Figure 9 shows the value of the strain at the variation of the distance between the stiffener $600 \mathrm{~mm}$ is $1.76 \mathrm{x}$ $10^{-3} \mathrm{~mm}$, the variation of the distance between the stiffener $700 \mathrm{~mm}$ is $1.77 \times 10^{-3} \mathrm{~mm}$, the variation of the distance between the stiffener $800 \mathrm{~mm}$ is $1.78 \times 10^{-3} \mathrm{~mm}$, The variation of the distance between $900 \mathrm{~mm}$ stiffeners is $1.79 \times 10^{-3} \mathrm{~mm}$, and the variation of the distance between $1000 \mathrm{~mm}$ stiffeners is $1.8 \times 10^{-3} \mathrm{~mm}$. There is an increase in the value of the strain as the distance between the stiffener increases with an average percentage increase of $0.6 \%$. In line with Tumurang's 2016 research, the shear force of the beam with a stiffener that is installed close to the support area is getting smaller, while the shear force will increase if the stiffener is placed in the field area [15].

The results of the stress-strain acting on each element in the car deck structure are detected, taking into account the variations in the stiffener distance that occur in each case, namely the stiffener distance variations of $600 \mathrm{~mm}$, $700 \mathrm{~mm}, 800 \mathrm{~mm}, 900 \mathrm{~mm}$ and $1000 \mathrm{~mm}$, where the distance increases stiffener in the structure, the value of stress and strain continues to increase, this proves the decreasing of the strength level of the vehicle deck as the stiffener distance increases. Referring to the yield strength value of the car deck material $370 \mathrm{~N} / \mathrm{mm}^{2}$, the optimal stiffener distance can be determined where in this study the optimal distance of $600 \mathrm{~mm}$ is obtained when viewed from the resulting stress magnitude of $285.5 \mathrm{~N} / \mathrm{mm}^{2}$ which does not exceed the yield strength of the material.

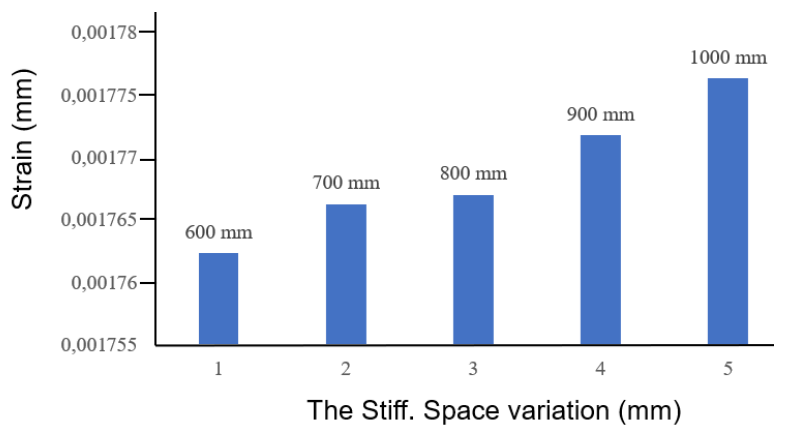

Figure 9. Strain influence of stiffener space
However, this value is not so accurate that further research is needed using a stiffener distance of $600 \sim 700$ $\mathrm{mm}$. This needs to be done because the simulation results are found with a stiff distance. $700 \mathrm{~mm}$ produces stress of $378,075 \mathrm{~N} / \mathrm{mm}^{2}$ which passes the yield strength of the material of $370 \mathrm{~N} / \mathrm{mm}^{2}$.

\section{Conclusions}

Stress-strain analysis on the car deck of the Ro-ro ferry ship which is influenced by variations in stiffener distance with a maximum evenly load condition of 1.18 $x 10^{-2} \mathrm{~N} / \mathrm{mm}^{2}$, it can be concluded that at the variation of the stiffener distance of $600 \mathrm{~mm}$ the maximum stress detected is $285.5 \mathrm{~N} / \mathrm{mm}^{2}$ and the maximum strain released is $1.76 \times 10^{-3} \mathrm{~mm}$. At the variation of the stiffener distance of $700 \mathrm{~mm}$, the maximum stress released is $378,075 \mathrm{~N} / \mathrm{mm}^{2}$ and the maximum strain released is $1.77 \times 10^{-3} \mathrm{~mm}$. For variations in the stiffener distance of $800 \mathrm{~mm}$, the maximum stress obtained is $383,737 \mathrm{~N} / \mathrm{mm}^{2}$ and the maximum strain released is 1.78 x $10^{-3} \mathrm{~mm}$. For the stiffener distance variation of 900 $\mathrm{mm}$, the maximum stress released is $389,188 \mathrm{~N} / \mathrm{mm}^{2}$ and the maximum strain released is $1.79 \times 10^{-3} \mathrm{~mm}$. At the variation of the stiffener distance of $1000 \mathrm{~mm}$, the maximum stress released is $425,388 \mathrm{~N} / \mathrm{mm}^{2}$ and the maximum strain released is $1.8 \times 10^{-3} \mathrm{~mm}$. The increase in the average stress value generated by $12.24 \%$ in the car deck construction is influenced by the increase in the distance between the stiffeners. Likewise, the value of the strain detected was increasing by an average of $0.6 \%$ with increasing distance between the stiffeners.

\section{Acknowledgements}

Thanks to the Construction Drawing Design Laboratory and Ship Engineering Naval Architecture Program Kalimantan Institute of Technology for providing facilities in this research. Thanks also to the anonymous reviewer for his input and corrections so that this paper is worthy of publication.

\section{References}

[1] M. Shama, "Buckling of Ship Structures," Alexandria University, 2013.

[2] A. M. Nugraha et al., "Strength Behavior Analysis of Insert Plate for Placing Corner Fitting due to Container Load," IOP Conf. Ser. Mater. Sci. Eng., vol. 875, 2019.

[3] Y. Susatio, Basics of Finite Element Method. Yogyakarta: ANDI, 2004. [in Bahasa]

[4] D. M. Rasyid, Strength of Ship Structure. Jakarta: Pradnya Paramita, 2000. [in Bahasa]

[5] Hughes, F. Owen, and J. K. Paik, Ship Construction Analysis and Design. The Society of Naval Architecture and Marine Engineers, 2010.

[6] T. Lamb, Ship Design and Construction. New Jersey: SNAME, 2004.

[7] S. S. Bhavikatti, Finite Element Analysis. New Delhi: New age International Publisher, 2005.

[8] S. Moaveni, Finite Elemen Analisis: Theory And Application With ANSYS. United States of America: Pearson Prentice Hall, 2008.

[9] D. Gross, Engineering Mechanics 2 "Mechanics of Materials." London: Springer, 2011.

[10] Rosmani et al., "Study on Transverse Strength of the DeckContainer Ships Due to Laying All Containers on Deck," EPI Int. J. Eng., vol. 2, no. 2, pp. 178-184, 2019.

[11] BKI, Rules For The Classification and Construction Seagoing Ship, Volume II. Jakarta, 2021. 
[12] A. H. Kalam, "Technical Study of Car Deck Strength on the RoRo 500 GT Ferry Due to Changes in Load Using the Finite Element Method," J. Tek. Perkapalan, vol. 5, no. 1, pp. 174-185, 2017. [in Bahasa]

[13] S. N. and D. A. H. Patnaik, Strength of Materials. Amsterdam: Elsevier, 2004.
[14] A. I. Wulandari, Nurmawati, and A. Dianiswara, "Buckling Analysis Deck Plate of Ferry Ro-Ro," J. Wave, vol. 13, no. 1, pp. 1-6, 2019. [in Bahasa]

[15] O. M. Tumurang, "Analysis of Stiffener Layout Against Local Bending of Steel," J. Sipil Statik, vol. 4, no. 7, p. 407, 2016. [in Bahasa 